\title{
The Sponsor'S Overview of an it Project, According to it Project Managers Opinion
}

\author{
Leif Marcusson ${ }^{1}$ \\ ${ }^{1}$ School of Business and Economics, Linnaeus University, Sweden \\ Correspondence: Leif Marcusson, School of Business and Economics, Linnaeus University, Sweden, Kalmar \\ Nyckel, SE-39382 Kalmar, Sweden. Tel: 46(0)480-497-119. E-mail:1eif.marcusson@1nu.se
}

Received: April 16, 2018; Accepted: May 7, 2018; Published: May 9, 2018

\begin{abstract}
The project sponsor's achievement is critical for project success. Hence, this research studies Swedish IT project managers' opinion on IT project sponsors' work and their understanding of the project / deliverable. Data were collected by two surveys, in 2007 (public authorities/business, 94 participants), and in 2016 (public authorities, 82 participants). According to the findings, a minority (36\%) of the project managers valued the project sponsors' knowledge / understanding as high (4 and 5 on a 5-point scale). They valued the sponsors' understanding of the project's deliverable somewhat higher (about 40\%) than the understanding of IT and business (about 30\%), and of the overview of the project (about 30\%). Seen in the light of recent years' data-crimes, digital society, and importance of successful businesses, the project sponsor has a huge responsibility and must therefore act from a basis of sound knowledge and complete understanding of the IT project and its deliverable.
\end{abstract}

Keywords: project deliverable, project manager, project overview, project product, project sponsor, project success

\section{Introduction}

Cyber-crimes due to defective and insufficient security measures are part of our everyday lives in the new digital society. This applies to both individuals and companies / public authorities. A few examples of cyber-crimes (FBI, 2017) are ransomware, going dark, identity theft and online predators. "There were an estimated 3.6 million cases of fraud and two million computers misuse offences in a year" (BBC, 2017). In 2015, the global cost of cybercrime was estimated to $\$ 500$ billion and might reach $\$ 2$ trillion in 2019 (Laberis, 2016). "Businesses in all industries and of all sizes have been affected by the increased complexity, novelty and persistence of cyberattacks, with consequences ranging from the reputational to economic and legal." (WEF, 2016, p. 103).

In recent years, some serious IT related problems, consequences and crimes either happened or were disclosed, examples listed below.

- $\quad$ Ransomware in May 2017 where e.g. hospitals had to cancel operations (Aftonbladet, 2017; Daily Mail, 2017).

- The Swedish Transport Agency (Transportstyrelsen) signed an agreement of outsourcing that violated Swedish law (SVT, 2017b). Two ministers from the government and the agency's Director General was dismissed after this information was published (SVT, 2017c, 2017d).

- Swedish wind and hydropower plants are unprotected, the systems lack password and exist openly on the Internet (SR, 2017b).

- Uber was subjected to hacking; user and driver information were stolen. Uber paid $\$ 100.000$ to the hackers to destroy the information (SVT, 2017a).

- Different control systems in Swedish companies and public authorities have serious security deficiencies (SR, 2017a).

- Homeland Security hacked into Boeing 757 in September 2016 (CBS, 2017).

When introducing / implementing a new information system (henceforth IS) or information technology (henceforth IT), these commissions are often carried out by projects. Security and safety are inevitable parts of these projects. Further, to handle various security and safety issues usually increase the costs, which conveys a need for decisions concerning the project resources. With a lack of knowledge and understanding of the fundamental security and 
safety issues connected to IS/IT, it is easy for decision-makers to ignore these issues and instead focus on the costs that are connected to well carried out security / safety work. In a project, there are two fundamental roles: the project manager and the projects sponsor (PMI, 2013). The sponsor set the rules, i.e. the restrictions and limitations as concerns money and the knowledge requirements. The project manager and the project sponsor jointly share the responsibility for the whole picture, including the security / safety when it comes to the project and its deliverable. Together they can create success, deliver the demanded result / deliverable, and lead the project team. It should be mentioned, that it is common for Swedish people to regard IS and IT as about the same, or to put it more frankly, the conception of IT is applied no matter if it is IS or IT that is discussed for the time being. Consequently, it is a generally low understanding of the difference between IS and IT.

\subsection{Project Manager and Project Sponsor}

Having a dedicated project sponsor is highly important for the project result / success according to Ladek (Zetlin, 2012). Weis says, “I wouldn't do, even an IT infrastructure project, without an executive sponsor" (Zetlin, 2012, p. 22), an executive sponsor is a project sponsor from business management. Furthermore, an executive sponsor ought to have excellent relationships in the organisation, and should support the project manager. Both the sponsor's attitude and title can bee of importance.

"The project manager and the sponsor are the ultimate power couple: They're stronger together than apart" (Bertsche, 2014, p. 50). The sponsor's role is to represent the stakeholders, the project manager's role is to lead the project team, to steer the project work, and to be the project's representative in the discussions / negotiations with the sponsor. An involved and enthusiastic sponsor strengthens the possibility of project success. The seven steps that lead to stronger relationship between these two roles are according to Bertsche (2014): (i) "Talk early and often", (ii) "Make it personal", (iii) "Build the team together", (iv) "Speak the same language", (v) "Help me help you", (vi) "Anticipate surprises", and (vii) "Stay in your lane" (Bertsche, 2014, pp. 52-55).

The relationship between the project manager and the sponsor requires a delicate act of balance. It is built upon mutual respect, where trust is a critical part. A way of earning the sponsor's confidence is to provide information that is structured, and timely delivered. As well as to put all the cards on the table, instead of trying to hide any information from the sponsor. A project manager would probably need to adjust your manners according to the sponsor and the situation (PMI, 2015).

An active project sponsor is most likely to have an impact on the project's success (PMI, 2014). However, for that to happen, the sponsor needs to be engaged, and to stay motivated during the whole project. That is to say, not only in the beginning. Further, the sponsor must be seriously interested in the result / outcome / deliverable. "When sponsors see themselves as a contributing member of the team, they understand their role in the successful delivery of the project and are much more invested overall" (PMI, 2014, p. 19). According to Merrick (2014), the sponsor's involvement in the project is important in order to avoid project failure. It is particularly interesting to notice that the project's ending is dependent of how it starts. For a good start "people need to have the objectives in mind all the time" (Merrick, 2014, p. 58), a short, summarized document could be helpful for achieving this.

\subsection{Some Statistics about Projects}

Statistics from The Standish Group's Chaos report (Project Smart, 2014) shows that 31.1 percent of projects will be cancelled, and 52.7 percent costs 189 percent over budget. Furthermore, 16.2 percent will complete the projects on time and within budget. The three most important success factors are; (i) "User involvement" 15.9 percent, (ii) "Executive management support" 13.9 percent, and (iii) "Clear statement of requirements" 13 percent (Project Smart, 2014, p. 8). The three most challenging factors for projects are (i) "Lack of user input" 12.8 percent, (ii) "Incomplete requirements \& specifications" 12.3 percent, and "Changing requirements \& specifications" 11.8 percent (Project Smart, 2014, p. 9). The three factors that describe, "why projects are impaired and ultimately cancelled" are: (i) "Incomplete requirements" 13.1 percent, (ii) "Lack of user involvement" 12.4 percent, and (iii) "Lack of resources" 10.6 percent (Project Smart, 2014, p. 9).

A report from PMI (Project Management Institute) about executive sponsor engagement (PMI, 2014, p. 2) shows that the average sponsor "work on three projects or programs at a time, spending an average of 13 hours per week on each project or program". It is also emphasized that communication between the project manager and the sponsor ought to take place in both directions. During the years 2012 to 2014, the level of active sponsors was 63 percent (i.e. $37 \%$ were not active). Three factors influence the possibility to enable or inhibit an active sponsor: (i) "Culture of project management that enables sponsors to avoid being overextended", (ii) "Communication", and (iii) "Development of executive sponsors" (PMI, 2014, p. 7). If a sponsor is overextended, (i) 33 percent have negative impact of removing hinders, (ii) schedule delays, and (iii) decision-making delays (ibid, p. 8). Sponsor training is carried out in 60 percent of the studied organizations. Projects with trained sponsors deliver projects (i) 
on time to a degree of 57 percent versus 46 percent without sponsor training, (ii) within budget, 62 percent versus 51 percent, and (iii) with a scope creep at 39 percent versus 50 percent if the sponsors did not get any training.

The PMI report "The high cost of low performance" (PMI, 2016) shows "that when organizations embrace project, program, and portfolio management practices, they have better outcomes" (PMI, 2016, p. 4). Eight percent said that development of executive sponsor skills had a very high priority, 21 percent said that it was somewhat high, 31 percent moderate, 23 percent somewhat low, and 17 percent very low (PMI, 2016, p. 24). According to senior executives, the figures for the level of priority concerning "development of skills for executive sponsors of projects" were as follows: 26 percent said it was very high, 35 percent somewhat high, 25 percent moderate, 12 percent somewhat low, and three percent said it was very low (PMI, 2016, p. 27). The same question answered by PMO (Project / Program Management Office) directors gave eight percent, 21 percent, 30 percent, 24 percent, and 17 percent (PMI, 2016, p. 30) respectively.

\subsection{Research Focus}

The respondents are IS/IT project managers in Sweden (surveys carried out in 2007 and in 2016). The questions concern how the project manager values (i.e. project managers opinion about) the sponsor and her/his work when it comes to IT projects.

The research questions more specifically concern how IT project managers perceive IT project sponsors' attitudes to IT projects.

1. What is the sponsor's understanding of IT as a part of business?

2. What is the sponsor's understanding of IT as the project's deliverable?

3. What is the sponsor's overview of the project?

4. What is the trend, if any, when the findings from 2007 and 2016 are compared?

\section{Theory}

The project sponsor is an individual, or a group of individuals, that provides the project with resources and support. Furthermore, the sponsor could be seen as a prerequisite for project success and the sponsor is the initiator, or is representing the initiator (PMI, 2013). The role as a project sponsor serves as the "Interface between the client team and supply team via the project manager, as the main day-to-day client representative" (OGC, 2007) and is the "main driving force behind a programme or project" (Axelos, 2017, p. 12). It is possible to say that the two roles (project manager and project sponsor) are the "main actors on the scene" and that they contribute to project success or the opposite (Chiucchi \& Giuliani, 2017). Further, they mean that the sponsor could be seen as the first believer of the deliverable and therefore could give it the legitimization that is necessary.

The success factors that the business must ensure are; (i) established and understood needs, (ii) approval of investment decision maker, (iii) right senior responsible owner, (iv) right suppliers, (v) an integrated team, (vi) right project manager, (vii) analysed and planned impact and outcome, (viii) delegated authority, (ix) defined and understood roles and responsibilities, and (x) a procurement route, which supports and facilitates integrated teamwork (OGC, 2007). Tilk (2016) gives five tips to the new sponsor: (i)"Understand the key value drivers and keep the focus on the big picture", (ii) "Define the structures, roles, responsibilities and processes", (iii) "Make decisions: Do not receive updates passively", (iv) "Ask the right questions: Challenge, challenge, challenge!", and (v) "Contribute to a strong tone at the top" (Tilk, 2016, pp. 24-25).

It takes good project governance to achieve success, e.g. as regards delivery and performance (Too, Tiendung \& Wei, 2017), it takes good stakeholder management (the sponsor included) to achieve success (Burga \& Rezania, 2017; Mauro \& Marly, 2017), and to have a strategic perspective (Mauro \& Marly, 2017). The sponsor will be judged by the deliverables (from the intended use) (Burga \& Rezania, 2017) and therefore they are the ones that should define the deliverables (Chiucchi \& Giuliani, 2017).

According to Kloppenborg, Tesch, Manolis and Heitkamp (2006, p. 24) the behaviour of the project sponsor correlates to project success as follows: (i) "defining project performance and success", (ii) "mentoring the project manager", (iii) "establishing communications and commitment", (iv) "defining and aligning the project", (v) "prioritizing the project", and (vi) "selecting and establishing the project team".

Project sponsorship is to be seen (i) "as a multi-dimensional construct", (ii) "being supportive of the project manager, team and project management", and (iii) "being particularly influential in achieving positive project outcomes" (Bryde, 2007, p. 807). 
In order to succeed in achieving customer satisfaction, as regards the project deliverables, the project sponsor ought to focus on communication, and it should be a top priority during the executing stage (Kloppenborg, Tesch $\&$ Manolis, 2014). Project manager and sponsor have to communicate actively and should not only rely on written reports (Burga \& Rezania, 2017). They should also influence / be influenced by inter-relationship with the organization e.g. with managers and employees (Chiucchi \& Giuliani, 2017).

To increase the possibilities for correctly carrying out the project job, the following should be attended to; the project sponsor should (i) "play an active role" and (ii) "his credibility and position" is essential, furthermore, the sponsor should (iii) "make the project manager's life immeasurably easier", and (iv) "improve the odds for project success" (Patton \& Shechet, 2007, pp. 8-9).

An important success factor is that the project's sponsor, as well as the project manager, fulfil the expectations from the stakeholders (Sewchurran \& Barron, 2008). Project management both as concerns the project manager and the project sponsor "should be conceptualized as a collective activity rather than an individual effort" (Burga \& Rezania, 2017, p. 1034). Value for money is important and when it comes to a construction project it would mean to assure (i) "lowest whole-life cost", (ii) "lowest cost for a given quality", (iii) "satisfied end user", (iv) "highest quality for given cost", and (v) "consistent quality" (Gibb \& Isack, 2001, p. 49). The sponsor can pursue a picture of getting as high return on the venture as possible (Garcia-Bernabeu, Benito, Bravo \& Pla-Santamaria, 2015), and can also look for cost-effective options and reduce long-term costs (Attarzadeh, Chua, Beer \& Abbott, 2017). Additionally, a procedure to guarantee revenue could help the sponsor to work with uncertainties and risks (Attarzadeh et al., 2017).

One of four important elements for "clear delineation of roles between governance and management" concerns the project sponsorship. The following are highlighted as critical: (i) "providing the direct link between the executive and the project or program manager" and (ii) "focused on the whole project lifecycle leading to the delivery of value" (Too \& Weaver, 2013, p. 1391).

It is central for the sponsor to follow the project's progress in order to be able to discover any deviation regarding time and/or cost, for the possibility to take action to correct these problems in due time (Wright, 1997). Furthermore, the sponsor must take on "some responsibility for achieving the project's objective" (Burga \& Rezania, 2017, p. 1034).

The project sponsor has a complex situation to master in order to fulfil its project role that involves: (i) "juggling the multiple needs of stakeholders and users groups", (ii) "departmental procedures and practices", (iii) "pangovernment edicts", and (iv) "sense of public probity and equity with an industry motivation by profit" (Hall et al., 2003, p. 501). At the same time, the sponsor is representing the client and acts on a daily basis as a manager.

Implications as "modern CIOs [sic Chief Information Officer] should not only count on their IT skills/knowledge but also equip themselves with specific business management competency" (Chen \& Wu, 2011, p. 153) shows how very important IT is for business, which is to say that the CIO also must take on responsibility for business (not only for IT). Furthermore, the back of the coin is that business management have a responsibility for IT e.g., "CEOs [sic Chief Execution Officer] and CFOs [sic Chief Financial Officer] along with CIOs are held accountable for serious IT problems associated with firms' financial reporting systems" (Masli, Richardson, Weidenmier Watson \& Zmud, 2009, p. 24).

\section{Methodology}

The research was conducted in a deductive way and did not receive any specific grant from funding agencies in the public, commercial, or not-for-profit sectors. Before the first data collection in 2007 the area had been studied for several years, and resulted in a thesis (Blank until review, 2008). Before the use in 2007 the questions were tested and corrected. Hence, the second data collection carried out in 2016 did not need further test.

In 2007, both private and public sector were included, with 94 respondents from 57 businesses and 37 public authorities. In 2016, the survey focused on the public sector, with 82 respondents from 73 public authorities.

Six of total 144 questions from the survey is used here: Q34 (Question number 34), Q48, Q85, Q86, Q111, and Q122 (see Findings section). These questions are formulated according to a five-point scale; five is the highest value, i.e. in the sense that it is most positively valued.

Additionally, six questions about the respondent profile was collected (table 1). The answers give a sense of the group of IT project managers who are respondents and the size of company / authority (respondents profile presented in method instead for in Results from survey). 
Table 1. Respondent profile.

\begin{tabular}{|c|c|c|c|c|c|}
\hline$\#$ & Area & Possible answer & Answers 2007 & Answers 2016 & Total \\
\hline \multirow[t]{3}{*}{ Q1 } & Year of birth & & Median 1961 & Median 1967 & \\
\hline & & Born year & 1940-1978 & 1951-1985 & \\
\hline & & & $29-67$ years old & $31-65$ years old & \\
\hline \multirow[t]{2}{*}{ Q2 } & Gender & Male & 61 & 46 & 107 \\
\hline & & Female & 33 & 36 & 69 \\
\hline \multirow[t]{6}{*}{ Q6 } & Size (number of employees) of company & Up to 50 & 8 & 2 & 10 \\
\hline & & $51-100$ & 2 & 3 & 5 \\
\hline & & $101-250$ & 6 & 8 & 14 \\
\hline & & $251-500$ & 6 & 5 & 11 \\
\hline & & $501-1000$ & 3 & 14 & 17 \\
\hline & & Over 1000 & 69 & 50 & 119 \\
\hline \multirow[t]{5}{*}{ Q7 } & Years of employment at current employer & Up to 3 & 0 & 32 & 32 \\
\hline & & $4-6$ & 16 & 16 & 32 \\
\hline & & $7-10$ & 19 & 11 & 30 \\
\hline & & $11-20$ & 22 & 16 & 38 \\
\hline & & Over 20 & 11 & 7 & 18 \\
\hline \multirow[t]{5}{*}{ Q8 } & Years of employment in profession & Up to 3 & 6 & 8 & 14 \\
\hline & & $4-6$ & 9 & 8 & 17 \\
\hline & & $7-10$ & 22 & 9 & 31 \\
\hline & & $11-20$ & 26 & 29 & 55 \\
\hline & & Over 20 & 31 & 28 & 59 \\
\hline \multirow[t]{5}{*}{ Q9 } & Project manager certification & PMI & 0 & 3 & 3 \\
\hline & & IPMA & 10 & 7 & 17 \\
\hline & & Companies own & 10 & - & 10 \\
\hline & & Other & 9 & 22 & 31 \\
\hline & & Not & 65 & 50 & 115 \\
\hline
\end{tabular}

Q1 "years old" shows the age at the time the respondent answered the survey (2007 or 2016).

Q1 to Q9 column 4-6 is numbers of answer from respondents.

Q9 as concerns the 2016 survey, "Companies own" and "Other" was combined into "Other".

Data analysing was done in Excel by counting the numbers of answers (e.g. number of answers with value 1 for Q34), by computing mean values, and medians value of the questions. Some correlations were also calculated.

\section{Results from Survey}

The six question used from the survey that are included in this research are:

- $\quad$ Q34 - How familiar is the sponsor with the information system (before launching the project)

- $\mathrm{Q} 48$ - To what extent do you consider the sponsor to see the difference between technical (IT) issues and business issues?

- Q85 - To what extent do you consider the sponsor to have an overview of the project?

- Q86 - To what extent do you consider the sponsor to have an overview of the project's deliverable?

- Q111 - How well do you know or understand the sponsor's strategy for the deliverable?

- Q122 - How good leadership, do you think the sponsor is practicing to the users of the information system?

The mean and median values for each question (table 2), and the actual counts / frequencies (table 3) provide an overview of the project managers' assessment of the project sponsors.

Table 2. Mean and median answers 


\begin{tabular}{|c|c|c|c|c|c|c|c|}
\hline & & Q34 & Q48 & Q85 & Q86 & Q111 & Q122 \\
\hline \multirow[t]{2}{*}{2007} & Mean & 2.9 & 3.1 & 3.1 & 3.2 & 3.6 & 2.8 \\
\hline & Median & 3 & 3 & 3 & 3 & 4 & 3 \\
\hline \multirow[t]{2}{*}{2016} & Mean & 2.9 & 3.0 & 3.3 & 3.0 & 3.4 & 2.9 \\
\hline & Median & 3 & 3 & 3 & 3 & 4 & 3 \\
\hline \multirow[t]{2}{*}{ Both years } & Mean & 2.9 & 3.1 & 3.2 & 3.1 & 3.5 & 2.9 \\
\hline & Median & 3 & 3 & 3 & 3 & 4 & 3 \\
\hline
\end{tabular}

Both years means that the total answers provided the basis for the calculation.

Notable in Table 2 is that five questions' value is about three, Q111 differs from the other questions since it has a mean value of 3.5 and a median value of 4 . Further, it is the only question, included in this research asking about what the project manager opinion about his/her owns understanding of the sponsor's strategy for the deliverable. That is to say, in that case it does not concern any judgement about the sponsor's strategy for the deliverable. Instead, it is about ranking, on the scale $1-5$, how up he/she, as an IT project manager, is on the sponsor's strategy for the deliverable.

Table 3. Counts (\#) and percent (\%) of answers

\begin{tabular}{|c|c|c|c|c|c|c|c|c|c|c|c|c|c|c|}
\hline & \multirow[t]{2}{*}{ Value } & & \multicolumn{2}{|c|}{ Q34 } & \multicolumn{2}{|c|}{ Q48 } & \multicolumn{2}{|c|}{ Q85 } & \multicolumn{2}{|c|}{ Q86 } & \multicolumn{2}{|c|}{ Q111 } & \multicolumn{2}{|c|}{ Q122 } \\
\hline & & & $\#$ & $\%$ & $\#$ & $\%$ & $\#$ & $\%$ & \# & $\%$ & $\#$ & $\%$ & $\#$ & $\%$ \\
\hline 2007 & 1 & & 3 & 3 & 0 & 0 & 2 & 2 & 2 & 2 & 3 & 3 & 7 & 7 \\
\hline \multirow[t]{4}{*}{$(\mathrm{N}=94)$} & 2 & & 32 & 34 & 26 & 28 & 20 & 21 & 20 & 21 & 7 & 7 & 25 & 27 \\
\hline & 3 & & 35 & 37 & 35 & 37 & 43 & 46 & 39 & 41 & 27 & 29 & 38 & 40 \\
\hline & 4 & & 22 & 23 & 27 & 29 & 27 & 29 & 21 & 22 & 45 & 48 & 24 & 26 \\
\hline & 5 & & 2 & 2 & 6 & 6 & 2 & 2 & 12 & 13 & 12 & 13 & 0 & 0 \\
\hline 2016 & 1 & & 9 & 11 & 13 & 16 & 1 & 1 & 7 & 9 & 5 & 6 & 10 & 12 \\
\hline \multirow[t]{4}{*}{$(\mathrm{N}=82)$} & 2 & & 21 & 26 & 13 & 16 & 10 & 12 & 18 & 22 & 13 & 16 & 15 & 18 \\
\hline & 3 & & 29 & 35 & 27 & 33 & 39 & 48 & 31 & 38 & 16 & 20 & 34 & 41 \\
\hline & 4 & & 15 & 18 & 17 & 21 & 25 & 30 & 20 & 24 & 38 & 46 & 17 & 21 \\
\hline & 5 & & 8 & 10 & 12 & 15 & 7 & 9 & 6 & 7 & 10 & 12 & 6 & 7 \\
\hline Both years & & 1 & 12 & 7 & 13 & 7 & 3 & 2 & 9 & 5 & 8 & 5 & 17 & 10 \\
\hline \multirow[t]{4}{*}{$(\mathrm{N}=176)$} & & 2 & 53 & 30 & 39 & 22 & 30 & 17 & 38 & 22 & 20 & 11 & 40 & 23 \\
\hline & & 3 & 64 & 36 & 62 & 35 & 82 & 47 & 70 & 40 & 43 & 24 & 72 & 41 \\
\hline & & 4 & 37 & 21 & 44 & 25 & 52 & 30 & 41 & 23 & 83 & 47 & 41 & 23 \\
\hline & & 5 & 10 & 6 & 18 & 10 & 9 & 5 & 18 & 10 & 22 & 13 & 6 & 3 \\
\hline
\end{tabular}

The percent figures are rounded to integers.

Pearson correlations between the six questions (both years together) are shown in Table 4, Grey cells show strong correlations according to Cohen's (1988) guidelines (i.e. medium strong = between .30 and .49), the correlations show a 2-tailed significance level at 0.01 .

Notable in Table 4 is: (i) two strong correlations, (ii) nine medium strong, and (iii) four week correlations.

There are only week correlations between respondents data and the six questions. For gender (Q2) the correlation is between -.003 and .086. For size of company (Q6) the correlation is between -.157 to .053. For years as project manager $(\mathrm{Q} 8)$ the correlation is between -.024 to .101 .

Table 4. Correlation Pearson (N=176) 


\begin{tabular}{|c|c|c|c|c|c|c|}
\hline & Q34 & Q48 & Q85 & Q86 & Q111 & Q122 \\
\hline Q34 & 1 & & & & & \\
\hline \multirow[t]{2}{*}{ Q48 } & $.419^{* *}$ & 1 & & & & \\
\hline & .000 & & & & & \\
\hline \multirow[t]{2}{*}{ Q85 } & $.413^{* *}$ & $.421 * *$ & 1 & & & \\
\hline & .000 & .000 & & & & \\
\hline \multirow[t]{2}{*}{ Q86 } & $.469 * *$ & $.484 * *$ & $.596^{* *}$ & 1 & & \\
\hline & .000 & .000 & .000 & & & \\
\hline \multirow[t]{2}{*}{ Q111 } & $.218 * *$ & $.280 * *$ & $.227 * *$ & $.284 * *$ & 1 & \\
\hline & .004 & .000 & .002 & .000 & & \\
\hline \multirow[t]{2}{*}{ Q122 } & $.443^{* *}$ & $.378^{* *}$ & $.476^{* *}$ & $.505^{* *}$ & $.374 * *$ & 1 \\
\hline & .000 & .000 & .000 & .000 & .000 & \\
\hline
\end{tabular}

\section{Discussion}

First part in discussion is about the difference between IT and business and it addresses Q48. Second is about IS/IT as the project's deliverable, and it addresses Q34, Q86, Q111, and Q122. Third concerns to have an overview of the project, and it addresses Q85. At the end is a comparison of the three parts is carried out. The findings have been amalgamated as follows: the values 1 and 2 on the scale are presented as Low, 3 as Middle, and 4 and 5 as $\mathrm{High}$. The motivation for presenting three levels, instead of five, is to better clarify the middle value and the values over and under the middle. Each sub-section is set up according to (i) a general analysis that connects to the theory section, (ii) Low value, (iii) Middle value, (iv) High value, and (v) a sum up that further connects to the theory.

\subsection{IT and Business}

The IT project sponsors understanding of the difference between IT and business is handled by Q48, which landed up at 3 as median value and 3.1 (3.1 in 2007 and 3.0 in 2016) as mean value. This can be seen as a low value if you are of the opinion that it is important to understand the difference between IT and business, because there are differences. Masli et al. (2009) stresses the importance of a top management that understands IT. When IT project sponsors make their contribution to the project business they must simultaneously realize that the IT is just as important to contribute to and that it cannot be forgotten. To forget about IT would affect the business negatively. If the IT would have been seriously regarded as important, or even critical, for the business, the answers to Q48 should have been higher (i.e. value High, 4 and 5) instead of just being ranked in the middle (i.e. Middle, 3 ) of the scale. According to OGC (2007), the sponsors connect business and project to each other, and the business will use the deliverable, from the project, to benefit the business. PMI (2013) stresses the sponsor as the initiator of the project or as the initiator's representative. Axelos (2017) emphasizes the sponsor as the driving force; Chiucchi and Giuliani (2017) regards the sponsor as the first believer of the projects' deliverables, and both these perspectives should lead to high value and good revenue. Chen and $\mathrm{Wu}$ (2011) highlights the business responsibility of CIO. Low (i.e. 1 and 2) and Middle values indicate that this is not the case in Swedish companies / public authorities. At least not according to the IT project managers that participated in this survey.

Low value ( 1 and 2) in 2007 was 26 counts (i.e. 28\%), in 201626 counts (32\%), and calculated as a whole (i.e. both years), the Low values were 52 counts (29\%). From 2007 to 2016, the percentages have increased with 32 percent, from 28 to 32 , i.e. the change calculated as a percentage. About one third of the IT project managers answered that according to their opinions; the sponsors do not understand the difference, which risks leading to a poorer solution compared with if the differences between IT and business had been sufficiently acknowledged by the sponsors. The findings, when the two surveys are compared (i.e. 2007 and 2016), show a rising trend concerning Low value. The figures are going in a direction that might cause the type of problems that are described in the introduction part. If the sponsors do not understand the IS/IT as well as the business there will be a huge risk that important issues connected to for example security / safety are downplayed and ignored.

Middle value (3) in 2007 was 35 counts (37\%), in 2016 it was 27 counts (33\%), and as a whole the figures were 62 counts (35\%). From 2007 to 2016 the percentage have fallen with 11 percent. This means that about one third of the IT project managers experience that the project sponsors either understand, or do not understand the difference, which is a result that is likely to convey ambivalence when it comes to decisions making. The Middle value also shows a downward trend between the two surveys.

High value (4 and 5) in 2007 was 33 counts (35\%), in 201629 counts (36\%), and for the whole (both years), High values were 62 counts (35\%). This means that about one third of the IT project managers believe that the project sponsors understand the difference; a result that points to good and sufficient solutions for the business as well as 
for the IT. The trend is flat, but it would be desirable to experience that the trend concerning the High value would be rising instead of just being flat.

The correlation between IT and Business (Q48) and Overview (Q85) is medium strong, while Q48's correlation with Deliverable (Q111) is weak and Q48's correlations with Q34, Q85, and Q122 are medium strong. This can to some extent strengthen the above results.

To sum up, IT and business' Low, Middle, and High values hold roughly one third each of the respondents' ranks, which actually indicates that two thirds do not consider it as important. The rising trend of low value, and the falling trend of middle value shows that more and more IT project sponsors understand less when it comes to acknowledging the differences between IT and business. Still, one third has a high value, but that is unfortunately too few for building / developing businesses in the digital society. Seen in the light of Chen and Wu (2011), Masli et al. (2009), OGC (2007), and PMI (2013) the sponsor have an important role when it comes to connect the project's deliverable (in this case IT) to business, but the result do not show that it is the case among Swedish companies / public authorities.

\subsection{The Deliverable of the Project}

The IT project sponsors' understanding of the IT project's deliverable, i.e. IS/IT, is based on four questions; Q34, Q86, Q111, and Q122 (see section 4). A calculation of the separate values for each question were summed up to a joint value that is accounted for. Overview, strategy, and users constitute the lens as regards the deliverable of the project. The medians are 3 (Q34), 3 (Q86), 4 (Q111), 3 (Q122) for 2007, 2016, and the same figures for both years (the whole). The means are 2.9, 3.2, 3.6, and 2.8 for 2007, 2.9, 3.0, 3.4, and 2.9 for 2016, and for the whole 2.9, 3.1, 3.5, and 2.9. The sponsor is one of the critical factors for project success (PMI, 2013; Burga \& Rezania, 2017; Mauro \& Marly, 2017; Too et al., 2017). Hence, if the sponsor does not see the deliverable (in this case IT) as important, the project manager apprehends that the project success is at risk. With Low or Middle values the projects risk to develop / deliver, a poor deliverable, e.g. an IT solution that lacks from e.g. security measures, which opens op for various kinds of cyber-crime.

One shortcoming can be communication that Kloppenborg et al. (2014) as well as Burga and Rezania (2017) emphasize as important. If these shortages concern the projects' deliverables, the public authorities have a serious problem. Bryde (2007), Burga and Rezania (2017) and Chiucchi and Giuliani (2017) stress sponsors' influence on the project outcome, i.e. the deliverable in this case IT, and Low and Middle values can be interpreted as a lack of sponsor influence. The sponsor can by its work, improve the odds for success (Patton \& Shechet, 2007). By fulfilling the stakeholders' expectations, the sponsor contributes to success (Sewchurran \& Barron, 2008). Furthermore, the sponsor's relationship with managers and employees also contributes to success (Chiucchi \& Giuliani, 2017). Project management is a collective activity in which both the project manager and the project sponsor take part (Burga \& Rezania, 2017). The survey findings do not support this. Sponsors are interested of the return of investment and they want it to be as high as possible (Garcia-Bernabeu et al, 2015), in a long-term perspective (Attarzadeh et al., 2017), and by applying procedures to avoid uncertainties and risks (ibid).

Low value (1 and 2) in 2007 was 99 counts (26\%), in 2016 Low value was 98 counts (26\%), and as a whole Low values were 197 counts (28\%). This means that about one quarter of the IT project managers' views on the IT project sponsors' knowledge and understanding (as regards the IT project's deliverable) were Low. The trend is flat according to the findings from both years' data collection. These Low values are alarming as regards the IT security / safety and the digital society, particularly due to the many threats and risks that are omnipresent.

Middle value (3) in 2007 was 139 counts (37\%), in 2016 it was 110 counts (34\%), and as a whole the Middle values were 249 counts (35\%). These findings show that about one third has a Middle value. Still, the trend is slightly falling (eight percent). It is however satisfying that the Middle values are bigger then the Low values. Still, it is not sufficiently good.

High value (4 and 5) in 2007 was 138 counts (37\%), in 2016 it was 120 counts (37\%), and as a whole 258 counts $(37 \%)$. These figures point to that two out of five IT project sponsors understand the IT project's deliverable. Even if it is rather good that two out of five convince the IT project managers that they thoroughly understand the deliverable, this is not good enough. The trend is flat, which is not so good either, since there is a huge need for a change into an upward trend in order to guarantee the success of IT projects even better.

The correlations between the questions Q34, Q111, and Q122, i.e. that are connected to deliverables, and IT and Business (Q48), as well as Overview (Q85) are week to medium strong. Nevertheless, the correlations between Q86 and Q85, and between Q86 and Q122 are strong. To some extent these findings might strengthen the above result. 
To sum up, the IT projects' deliverables have Low and Middle values if they are merged, i.e. three out of five $(60 \%)$. This result is slightly better than for IT and business (section 5.1) but it is not sufficiently good that only 40 percent of the IT project managers believe that the IT project sponsor have a high understanding. Seen in the view of Bryde (2007), Kloppenborg et al. (2014), Pattor and Shechet (2007), and Sewchurran and Barron (2008) the result for Swedish companies / public authorities is not promising for the possibility to create the deliverable (IS/IT) that the business requires and needs.

\subsection{The Project Overview}

The IT project sponsors' overview of the projects was handled by Q85. The calculations gave 3 as median and 3.2 (3.1 in 2007 and 3.3 in 2016) as mean values. OGC (2007) stresses ten success factors, Kloppenborg et al. (2006) highlight six success factors, and these can be seen as a way to acquire an overview. Tilk (2016) highlights five tips to a new sponsor and those can be regarded as a way to gain control and overview. Even as regards this perspectives, the findings shows too much of Low and Middle values as regards the possibility for the sponsor to have / achieve a sufficiently good overview. To deliver value for money is critical for projects (Too \& Weaver, 2013; Gibb \& Isack, 2001). Further, it is very important to follow up on the progress (Wright, 1997). The complex situation of a project sponsor (Hall et al., 2003) requires a good overview of the project in order to succeed. The sponsor provides the project with resources and support (PMI, 2013); to achieve this the sponsor needs to have an overview. The project sponsor has responsibility for the project's objectives, as well as for achieving those (Burga \& Rezania, 2017). This research findings show too many Low and Middle values, i.e. from the IT project managers' opinions, in order to indicate sufficient overview; instead, the research figures point to a lack of sponsor overview. At least in order to guarantee successful projects.

Low value (1 and 2) in 2007 was 22 counts (23\%), in 2016 it was 11 counts (13\%), and as a whole there were 33 counts (19\%). In this case, the figures show a falling trend, and the counts fall with 44 percent. This means that about one out of five of the IT project managers do not have an overview of the IT projects. Indeed, it is a good thing that the Low values are falling but there are still too many counts for Low; the findings indicate that too many IT project sponsors have an insufficiently overview.

Middle value (3) in 2007 was 43 counts (46\%), in 2016 it was 39 counts (48\%), and as a whole there were 82 counts $(47 \%)$. These figures point to that about half of the IT project managers believe that the IT project sponsors have at least some overview of the project. The trend is slightly rising $(4 \%)$ but actually, it is such a small difference that it can be seen as more or less flat. It is however, a good sign that there are more Middle values than Low.

High value (4 and 5) in 2007 was 29 counts (31\%), in 2016, it was 32 counts (39\%), and as a whole High value were 61 counts (35\%). These figures show that about one third of the IT project managers have marked High value (4 or 5 on the 5-point scale) for their opinion about how good the sponsors' overview of the project are. The trend is clearly rising, 26 percent, and it shows a relatively big difference. That is good, but still it was one out of three IT project managers, who did not consider that the sponsors had an overview that they would rank as High.

Correlations between Overview (Q85) and the other questions are week or medium strong, except the correlation between Q85 and Q86 that is strong. This points in a direction that strengthens the above result.

To sum up, according to the IT project managers, there are only one third that ranked the sponsors' overview of the IT projects as High (i.e. 4 and 5). With an insufficiently overview of the projects, the sponsors add to the risk of failure, resulting in less successful projects. The research result seen in the light of Gibb and Isack (2001), Hall et al (2003), Kloppenborg et al. (2006), OGC (2007), PMI (2013), Too and Wright (2013), and Wright (1997) shows low grade of overview.

\subsection{A Comparison of the Three Perspectives}

The three perspectives (from sections above) should also be scrutinized in comparison with each other (table 5) to fully understand the situation with IT project sponsors, from the IT project managers' opinions.

Table 5. A comparison of three perspectives

\begin{tabular}{llll}
\hline & $\begin{array}{l}\text { IT and } \\
\text { business }\end{array}$ & $\begin{array}{l}\text { Project } \\
\text { deliverable }\end{array}$ & Project overview \\
\hline Low & $1 / 3$ & $1 / 4$ & $1 / 5$ \\
\hline
\end{tabular}




\begin{tabular}{llll}
\hline Middle & $1 / 3$ & $1 / 3$ & $1 / 2$ \\
High & $1 / 3$ & $2 / 5$ & $1 / 3$ \\
\hline
\end{tabular}

Rounded sum of year 2007 and 2016

High values are highly desired because that would mean that the IT project sponsors have a high understanding and great knowledge of the project, of the project's deliverable (IS/IT), and of its influence on the business. The sponsors' understanding and knowledge are stressed by Bryde (2007), Chen and Wu (2011), Gibb and Isack (2001), Hall et al. (2003), Kloppenborg et al. (2006, 2014), OGC (2007), Masli et al. (2009), Patton and Shechet (2007), PMI (2013), Sewchurran and Barron (2008), Too and Weaver (2013), and Wright (1997).

As is evident in Table 4, this was not the case for this research. The High value alternatives (4 and 5) were marked in about $30(1 / 3)$ to 40 percent (2/5) of the respondents' answers. These results indicate that problems are more likely to occur, with a high potential to bring about an increased risk for cyber-crimes of various kinds.

Another way of presenting the research findings is to combine the two surveys' results (table 6). The table could be explained as follows: Value gives the numbers of answer, i.e. Low represents the values 1 and 2, Middle is value 3 , and High represents the amalgamated values 4 and 5. There are six questions behind Table 6, meaning that as concerns Low and High it is 12 (two times six) because these include two values; 1 and 2 for Low, 4 and 5 for $H i g h$. The mean value is the value divided with the number of questions (i.e. 6). The percent (\%) shows the values divided by the value sums respectively.

Table 6. Six questions presenting the whole

\begin{tabular}{lllll}
\hline & Value count $\#$ & Numbers of Q & Mean value & \% \\
\hline Low & 282 & 12 & 23.5 & 26.7 \\
Middle & 393 & 6 & 65.5 & 37.2 \\
High & 381 & 12 & 31.8 & 36.1 \\
Sum & 1056 & 30 & 35.2 & \\
\hline
\end{tabular}

Sum of year 2007 and 2016

Table 6 shows a reinforcement of the previously presented results. There is only 36 percent with high value, which corresponds to what is earlier shown in Table 4. Only a minority of the sponsors to take their responsibility seriously. This judgement comes from the IT project managers' answers and shows that the sponsors have been able to show to the IT project managers that they have a sufficiently good understanding and knowledge about the projects and the deliverables from the projects. The downside of this result is however, that a majority of the sponsors (Low and Middle value) have not been convincing as regards these aspects in their collaboration with the IT project managers.

\section{Conclusions}

The first research question is: "What is the sponsor's understanding of IT as a part of business?". The answer is that one third each for values Low, Middle, and High indicate that the sponsors have a substandard understanding; at least according to IT project managers' opinions.

The second research question is: "What is the sponsor's understanding of IT as the project's deliverable?". The answer is Low and Middle values of understanding for 60 percent of the project sponsors, i.e. according to IT project managers' opinions. It must be seen as a risky situation when only 40 percent of the sponsors have a high understanding of the projects' deliverables. Because, having a high knowledge and understanding should be seen as an important prerequisite for a successful outcome.

The third research question is: "What is the sponsor's overview of the project?". The answer is that High value concerning the sponsors' overview of the project was found for a third of the project sponsors. That result point to a big risk for the IT project manager's possibilities to do his / her work, and for the project success as a whole.

The first three questions seen as a whole highlights the fact that the findings show Low and Middle values by two thirds, mostly medium strong correlations. This indicates a huge risk factor, which should be taken under serious consideration. Efforts must be put on searching for ways to lower the figures behind these findings. 
The fourth research question is: "What is the trend, if any, when the findings from 2007 and 2016 are compared?". The answer is that the research findings do not actually point to a trend when they are amalgamated as a whole. However, some figures separately show signs of a trend (at least to 10 percent):

- IT and business

- Low value is increasing with $21 \%$

- Middle value is decreasing with $11 \%$

- Project overview

- Low value is decreasing with $44 \%$

- High value is increasing with $26 \%$

A sum up these research findings' importance for IT projects, their outcome, and thereby for the IT project sponsors' responsibilities point to the following conclusions. The new digital society demands better IT and the IT project sponsors should conduct a work that both businesses and public authorities really need in order to exist safely, without data integrity loss in the new society. Lack of clearly outspoken responsibility for these important issues might increase cyber-crime against public authorities and companies. A good start would be if the IT project sponsors took a lead on these matters, since IT development and IT implementations are often carried out by projects. Hence, the sponsors, who are those that set the criteria and follow the projects throughout the processes, would have even more than a fair chance to positively influence the future IT solutions.

Further research focusing on how the project sponsor / top management understand their roles and responsibilities could be a possible next step. That would for example make it possible to compare project managers' and project sponsors' views on project work.

\section{Acknowledgements}

Thanks to assistant professor (Blank until review) for co-operated with during the survey in 2016. Also, thank the respondents that participated in the two surveys (2007 and 2016).

\section{References}

Aftonbladet. (2017). Världsomspännande cyberattack - brittiska sjukhus drabbade [Worldwide cyber-attack - UK hospital victim], Aftonbladet. Retrieved November 22, 2017 from https://www.aftonbladet.se/nyheter/a/4pKo6

Attarzadeh, M., Chua, D. K. H., Beer, M., \& Abbott, E. L. S. (2017). Option-based negotiation management of PPP-BOT infrastructure projects. Construction management and economics, 35(11-12), 676-692. https://doi.org/10.1080/01446193.2017.1325962

Axelos. (2017). Managing successful projects with PRINCE2. Norwich England: TSO.

BBC. (2017). Cybercrime and fraud scale revealed in annual figures. Retrieved November 22, 2017 from http://www.bbc.com/news/uk-38675683, 2017-01-19

Bertsche, R. (2014). 7 steps to stronger relationships between project managers and sponsors, PM Network. (September), 50-55, Retrieved from www.pmi.org

Bryde, D. (2007). Perceptions of the impact of project sponsorship practices on project success. International Journal of Project Management, 26(8),800-809. https://doi.org/10.1016/j.ijproman.2007.12.001

Burga, R., \& Rezania, D. (2017). Project accountability: An exploratory case study using actor-network theory. International Journal of Project Management. 35(6), 1024-1036. https://doi.org/10.1016/j.jproman.2017.05.001

CBS. (2017). Experts working with Homeland Security hacked into Boeing 757. Retrieved November 10, 2017 from https://www.cbsnews.com/news/homeland-security-hacked-boeing-757-jetliner/

Cheng, Y. C., \& Wu, J. H. (2011). IT management capability and its impact on the performance of a CIO. Information \& Management, 48(4), 145-156. https://doi.org/10.1016/j.im.2011.04.001

Chiucchi, M. S., \& Giuliani, M. (2017). Who's on stage? The roles of the project sponsor and the project leader in IC reporting, The Electronic Journal of Knowledge Management, 15(3), 183-193

Cohen, J. W. (1988). Statistical power analysis for behavioural sciences (Second Edition). Hillsdale, NJ, USA: Lawrence Erlbaum Associates.

Daily mail. (2017). NHS is hit by large-scale cyber attack with patients turned away and operations cancelled in 
hospitals across Britain as hackers take over computers and demand cash not to wipe out records, Daily Mail. Retrieved November 22, 2017 from https://www.dailymail.co.uk/news/article-4500080/NHS-computersystems-phones-cyber-attack.html

FBI. (2017). Cyber Crime. Retrieved November 22, 2017 from https://www.fbi.gov/investigate/cyber

Garcia-Bernabeu, A., Benito, A., Bravo, M., \& Pla-Santamaria, D. (2015). Photovoltaic power plants: a multicriteria approach to investment decisions a case study in western Spain. Annals of Operations Research, 245,163-175. https://doi.org/10.1007/s10479-015-1836-2

Gibb, A.G.F. \& Isack, F. (2001). Client drivers for construction projects: implications for standardization. Engineering, Construction and Architectural Management, 8(1), 46-58

Hall, M., Holt, R., \& Purchase, D. (2003). Project sponsors under New Public Management: lessons from the frontline, International Journal of Project Management, 21(7), 495-502. https://doi.org/10.1016/S02637863(02)00054-6

Kloppenborg, T. J., Tesch, D., \& Manolis, C. (2014). Project success and executive sponsor behaviors: Empirical life cycle stage investigations, Project Management Journal, 45(1), 9-20. https://doi.org/10.1002/pmj.21396

Kloppenborg, T. J., Tesch, D., Manolis, C., \& Heitkamp, M. (2006). An empirical investigation of the sponsor's role in project initiation. Project Management Journal, 37(3), 16-25.

Laberis, B. (2016). 20 Eye-opening cybercrime statistics. Retrieved November 22, 2017 from https://securityintelligence.com/20-eye-opening-cybercrime-statistics/

Marcusson, L. (2008). Assymetriskt påverkat beslutsfattande in IT-projekt [Asymetrcal influenced decision making in IT project], Thesis, Åbo Academy University, Åbo Academy University Press

Masli, A., Richardson, V. J., Weidenmier Watson, M., \& Zmud, R. W. (2009). CEO, CFO \& CIO Engagement in Information Technology Management: The Disciplinary Effects of Sarbanes-Oxley Information Technology Material Weaknesses. In Proceedings of the University of Waterloo Centre for Information Integrity \& Information Systems Assurance 6th Bi-Annual Research Symposium. Toronto, Ontario, Canada. Retrieved December $3, \quad 2017 \quad$ from http://citeseerx.ist.psu.edu/viewdoc/download;jsessionid=EFC082507574A8BC46410897359CA3B5?doi= 10.1.1.457.4880\&rep=rep1\&type $=$ pdf

Mauro, L. M., \& Marly, M. C. (2017). Key factors of sustainability in project management context: A survey exploring the project managers' perspective, International Journal of Project Management, 35(6), 1084-1102. https://doi.org/10.1016/j.ijproman.2016.04.004

Merrick, A. (2014). And away we go. PM Network. July, pp. 56-61. Retrieved from http://www.pmi.org

OGC. (2007). Project organisation roles and responsibilities, Achieving excellence in construction procurement guide, London England: OGC - Office of Government Commerce.

Patton, N., \& Shechet, A. (2007). Wisdom for building the project manager/Project sponsor relationship: Partnership for project success. The Journal of Defense Software Engineering, 20(11), 4-9.

PMI. (2013). A Guide to the Project Management Body of Knowledge (Fifth Edition). Philadelphia, PA, USA: Project Management Institute.

PMI. (2014). Engaging sponsors, PM Network. (November), pp. 18-20. Retrieved from http://www.pmi.org

PMI. (2015). Managing up, PM Network. (August), pp. 22-23. Retrieved from http://www.pmi.org

Project Smart. (2014). The Standish Group Report Chaos - Project Smart Retrieved from https://www.projectsmart.co.uk/white-papers/chaos-report.pdf

Sewchurran, K., \& Barron, M. (2008). An investigation into successfully managing and sustaining the project sponsor - project manager relationship using soft system methodology. Project Management Journal. 39(S1), Supplement, S56-S68. https://doi.org/10.1002/pmj.20060

SR. (2017a). Ekot avslöjar: Tusentals it-system har allvarliga säkerhetsbrister [Ekot reveals: Thousands of IT systems have serious security shortcomings], Sveriges Radio. Retrieved November 27, 2017 from http://sverigesradio.se/sida/artikel.aspx?programid=83\&artikel $=6826493$

SR. (2017b). Gick att styra kraftverk utan lösenord [Went to control power plant without password], Sveriges $\begin{array}{lllll}\text { Radio. } & \text { Retrieved } & \text { November } & 22, & 2017\end{array}$ http://sverigesradio.se/sida/artikel.aspx?programid $=83 \&$ artikel $=6826610$ 
SVT. (2017a). Uber mörkade dataintrång - betalade hackare för att hålla tyst [Uber darkened hacking - paid hackers to keep quiet], Sveriges Television. Retrieved November 22, 2017 from https://www.svt.se/nyheter/utrikes/uber-morkade-dataintrang-betalade-hackare-for-att-morka

SVT. (2017b). SVT Nyheter avslöjar: Läckte uppgifter vid dataupphandling [SVT News reveals: Leaked data at IT procurement], Sveriges Television. Retrieved November 22, 2017 from https://www.svt.se/nyheter/inrikes/svt-avslojar-dataupphandling-agrens-fall

SVT. (2017c). Jag hade hoppats få fortsatt uppdrag inom staten [I had hoped to continue mission in the state], Sveriges Television. Retrieved November 22, 2017 from https://www.svt.se/nyheter/inrikes/agrensfackforbund-beklagar-avskedsbeslutet

SVT. (2017d). Maria Ågren avskedas [Maria Ågren is dismissed], Sveriges Television. Retrieved November 22, 2017 from https://www.svt.se/nyheter/inrikes/nytt-besked-om-maria-agren

Tilk, D. (2016). The New Sponsor, PM Network. (January), pp. 24-25. Retrieved from http://www.pmi.org

Too, E. G., \& Weaver, P. (2013). The management of project management: A conceptual framework for project governance, International Journal of Project Management, 32(8), 1382-1394. https://doi.org/10.1016/j.ijproman.2013.07.006

Too, E., Tiendung, L., \& Wei, Y. Y. (2017). Front-end planning - The role of project governance and its impact on scope change management, International Journal of Technology, 8(6), 1124-1133, https://doi.org/10.14716/ijtech.v8i6.708

WEF. (2016). The Global risks report $201611^{\text {th }}$ edition, World Economic Forum, Insight report. Retrieved December 3, 2017 from https://www.weforum.org/reports/the-global-risks-report-2016/

Wright, J. N. (1997). Time and budget: the twin imperatives of a project sponsor. International Journal of Project Management, 15(3), 181-186. https://doi.org/10.1016/S0263-7863(96)00059-2

Zetlin, M. (2012). Power of the executive sponsor. Computerworld. (December 3), 18-24

\section{Copyrights}

Copyright for this article is retained by the author(s), with first publication rights granted to the journal.

This is an open-access article distributed under the terms and conditions of the Creative Commons Attribution license (http://creativecommons.org/licenses/by/4.0/). 